\title{
Indentations on Air Plasma Sprayed Thermal Barrier Coatings Prepared by Different Starting Granules
}

\author{
Yong Suk Heo, ${ }^{1}$ Dong Heon Lee, ${ }^{1}$ Yeon-Gil Jung, ${ }^{2}$ and Kee Sung Lee ${ }^{1}$ \\ ${ }^{1}$ School of Mechanical Systems Engineering, Kookmin University, Seoul 136-702, Republic of Korea \\ ${ }^{2}$ School of Nano and Advanced Materials Engineering, Changwon National University, Changwon 641-773, Republic of Korea \\ Correspondence should be addressed to Kee Sung Lee; keeslee@kookmin.ac.kr
}

Received 15 April 2015; Revised 19 August 2015; Accepted 26 August 2015

Academic Editor: Albano Cavaleiro

Copyright (c) 2015 Yong Suk Heo et al. This is an open access article distributed under the Creative Commons Attribution License, which permits unrestricted use, distribution, and reproduction in any medium, provided the original work is properly cited.

\begin{abstract}
The effect of starting granules on the indentation properties of air plasma sprayed thermal barrier coatings (TBCs) is investigated in this paper. Various kinds of spray-dried granules are prepared from different processing conditions, especially varying solvent and dispersant, showing a deformed hollow-typed and a filled spherical-typed granule. The similar coating thicknesses are prepared by adjusting process parameters during air plasma spray. All XRD peaks in phase analysis are tetragonal and cubic phases without any monoclinic phase after the starting granules were heat-treated. A relatively porous microstructure of the coating layer could be obtained from the monodisperse granules, while a relatively dense microstructure resulted from the hollow-typed granules. The morphology and distribution of the granules crucially affect the microstructure of thermal barrier coatings and thus have influences on indentation properties such as indentation stress-strain curves, contact damage, and hardness. The implication concerning microstructure design of TBCs for gas turbine applications is considered.
\end{abstract}

\section{Introduction}

Thermal barrier coatings (TBCs) with typical 200 600 $\mu \mathrm{m}$ of thickness are widely used in gas turbine engine to protect superalloy substrates from hot gas or particle impact $[1,2]$. In order to decrease the thermal mismatch and to improve the adhesion between the coating and the substrate, a bond coat, $75 \sim 200 \mu \mathrm{m}$ of thickness, is usually deposited on the substrate, and then topcoat is finally applied $[3,4]$.

For preparing these TBCs, air plasma sprayed (APS) coating and electron beam physical vapor deposition (EBPVD) coating are widely used. While EBPVD coating shows superior strain tolerance and high calcium-magnesium-aluminosilicate (CMAS) resistance due to its columnar microstructure [5], the thermal conductivity of the EBPVD is usually higher and high manufacturing cost is also the main disadvantage of EBPVD coating. Air plasma coating has good advantages in being more economic and having relatively lower thermal conductivity.

Yttrium stabilized zirconia (YSZ) ceramics are the most widely used materials for thermal barrier coatings in the advanced gas turbine system, due to their low thermal conductivity, relatively high thermal expansion coefficient, comparable to metal substrate or bond coat and high mechanical strength [2]. The operating temperature tends to increase to over $1300^{\circ} \mathrm{C}$ to enhance the energy efficiency of a gas turbine system, which drives a new cooling system and an increase of TBC thickness and adjusting microstructures of the coating layer [3].

Microstructure of TBCs is determined by the feedstock granules as well as spraying conditions. In particular, the size, shape, and distribution of the starting granules are critical to the microstructure and are the most important parameters for the quality of TBCs. The thermal/mechanical resistances and failure mechanisms are closely related to the microstructure of TBCs, which is in turn influenced by the granule morphology [6-9]. In this thermal and mechanical resistance, wear resistance of $\mathrm{TBC}$ is important to prolong the lifetime of gas turbine system. One critical problem of the failures of TBCs is spallation or delamination of the coating layers due to mismatch of thermal expansion between the coating and the bond coat material. However, mechanical 


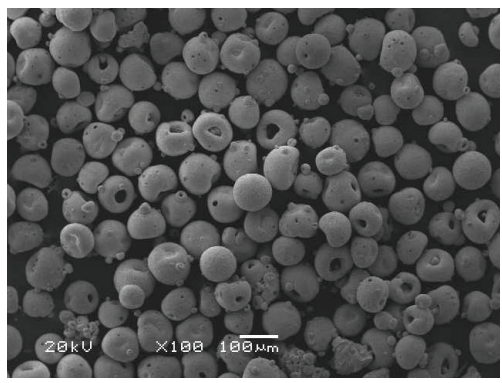

(a-1)

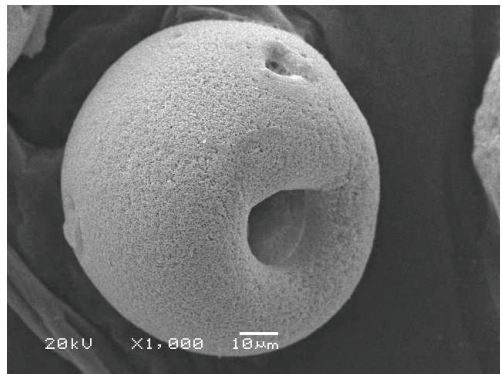

$(\mathrm{a}-2)$

(a)

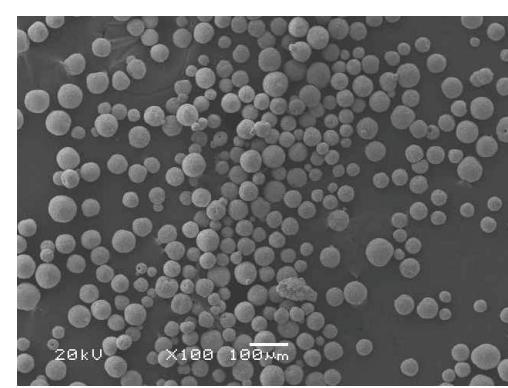

(b-1)

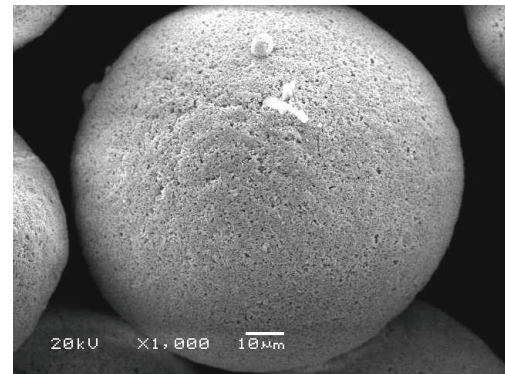

(b-2)

(b)

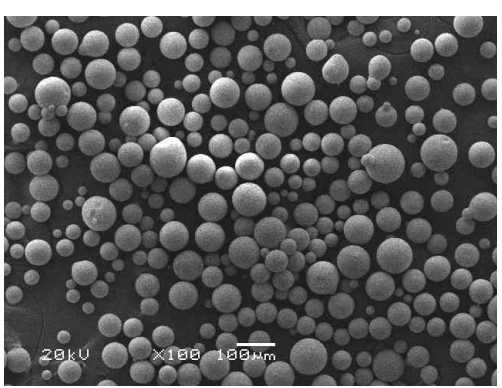

$(\mathrm{c}-1)$

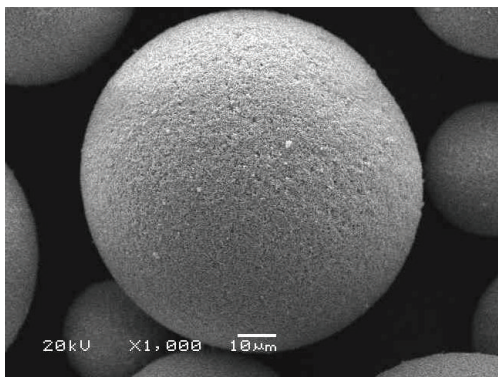

$(\mathrm{c}-2)$

(c)

FIGURE 1: SEM micrographs of spray-dried granules with different magnification: (a) YZ-WH, (b) YZ-AH, and (c) YZ-WD.

resistance such as wear or strain tolerance is the other required issue for resistance of spallation [3, 10-12].

Indentation techniques including nanoindentation and Hertzian indentation are used to characterize the mechanical properties of the thermal barrier coatings. A Hertzian contact test with a spherical indenter characterizes elastic and the quasiplastic properties of thermal barrier coatings [13-15]. Instrumented indentation techniques such as nanoindentations can be used to investigate contact damage, fracture, and mechanical properties related to wear of thermal barrier coatings $[16,17]$. Analysis studies on the indentation have gained attention with numerous papers covering the topic of TBC $[18,19]$.

In the present study the effects of morphology on spraydried granules, deformed hollow and filled spherical, on the indentation properties of air plasma sprayed TBCs are investigated using Hertzian indentation, microindentation, and nanoindentation. The indentation stress-strain curves of TBCs prepared from various staring granules are constructed by Hertzian indentation. Hardness $(H)$ values of top coat prepared from different starting granules are measured on the surfaces using microindentations. The localized mechanical characteristics, hardness and elastic modulus, are also measured and compared using nanoindentation technique in this study.

\section{Materials and Experimental Procedures}

Three starting granules were used to prepare for the $8 \mathrm{wt} . \%$ YSZ coated materials in the laboratory: YZ-WH (spraydried hollow granules in water base), YZ-AH (spray-dried hollow granules in alcohol base), and YZ-WD (spray-dried dense granules in water base). The $8 \mathrm{wt} \% \mathrm{YSZ}$ powders were synthesized from a coprecipitation in a zirconium oxychloride $\left(\mathrm{ZrOCl}_{2} \cdot 8 \mathrm{H}_{2} \mathrm{O}\right)$ solution, doped with yttrium nitrate, $\mathrm{Y}\left(\mathrm{NO}_{3}\right)_{3} \cdot 6 \mathrm{H}_{2} \mathrm{O}$. The mixed solution was neutralized with an $\mathrm{NH}_{3}$ solution. The reaction mixture was stirred for 30 minutes, filtered, washed with deionized water, and dried for 1 day and then calcined at $1000^{\circ} \mathrm{C}$ for $2 \mathrm{hr}$. After that, they were crushed and sieved. The sieved powders were dispersed again into slurry and ball milled for $24 \mathrm{hr}$ with an organic solvent, binders, and plasticizer. All powder batches were mixed using $\mathrm{Al}_{2} \mathrm{O}_{3}$ balls with 30 vol.\% of jar. The solvent in the slurry was distilled water or alcohol. The PVA 205 organic binder was added in water solution, while PVB binder was added in alcohol solution. LU6418 of dispersant was added for YZ-WH, PEG for YZ-AH, and no dispersant for YZ-WD. Constant inlet and outlet temperatures were varied within range of $170 \sim 210^{\circ} \mathrm{C}$ for inlet and $70 \sim 110^{\circ} \mathrm{C}$ for outlet during spray-drying. The atomizer speed was controlled in the range of $6,000 \sim 10,000 \mathrm{rpm}$. Therefore, three types of starting granules were prepared as shown in Figure 1. YZ-WH and YZ-AH show both hollow and filled spherical types, with a relatively porous structure. The YZ-WH consists of about 70 vol.\% hollow type and about 30 vol.\% (Figure 1(a)) filled spherical type, and the $\mathrm{YZ}-\mathrm{AH}$ is a reverse ratio of $30 \mathrm{vol} . \%$ and 70 vol.\% (Figure 1(b)) of the hollow and spherical types. On the other hand, the YZ-WD consists of $100 \%$ of filled spherical types of granules (Figure 1(c)), respectively.

The spray-dried granules have been heat-treated to enhance the feeding ability during plasma spray coating. Heat treatments were conducted at $1250^{\circ} \mathrm{C}$ for 10 minutes after removing the binder and dispersant at a temperature of $600 \sim 800^{\circ} \mathrm{C}$. The heat-treated granules were classified using 
an auto-sieve machine with a stack of sieves, 38, 45, 75, 106, and $125 \mu \mathrm{m}$. The starting granules for APS coatings were selected in the size range of $45 \sim 106 \mu \mathrm{m}$. The properties of the feedstock for the coatings were reported in the previous literature [20].

A nickel-based alloy (Nimonic 263, Ni-20Cr-20Co5.9Mo-0.5Al-2.1Ti-0.4Mn-0.3Si-0.06C in wt.\%, ThyssenKrupp VDM, Germany) was prepared and sandblasted to enhance the adhesion force. Bond coat (AMDRY962, $\mathrm{Ni}-22 \mathrm{Cr}-10 \mathrm{Al}-1.0 \mathrm{Y}_{2} \mathrm{O}_{3}$, in wt.\%, Sulzer Metco Holding AG, Switzerland) materials were deposited on the Nimonic 263 substrate using 9MB (Metco 9MB, Sulzer Metco Holding AG, Switzerland) equipment with a thickness of $d=250 \pm 20 \mu \mathrm{m}$. The deposition conditions of the bond coat were $35 \mathrm{~g} / \mathrm{min}$ of feed rate, $228 \mathrm{~mm}$ of spray distance, and $3 \mathrm{~mm} / \mathrm{sec}$ of deposition speed. Finally, YSZ thermal barrier coatings from three starting granules, YZ-WH, YZ-AH, and YZ-WD, on the bond coats were deposited using TriplexPro-200 (Sulzer Metco, Switzerland) equipment. The coating thickness was maintained in the range of $d=600 \sim 700 \mu \mathrm{m}$ uniformly. Details of the deposition conditions of the APS processes are shown in Table 1.

The phases of the spray-dried granules were qualitatively analyzed using an X-ray diffractometer (XRD, D/Max2000Ultima Plus, Rigaku, Japan). The microstructure of the coating sections were investigated by scanning electron microscope (SEM, XL30 Philips). The samples coated by the APS process were cut and polished to a $1 \mu \mathrm{m}$ diamond paste in order to observe the cross-sectional microstructures including thickness of each TBC system prepared by the developed granules. The porosities and splat boundaries of the coating layers were quantitatively analyzed on 5 images for each condition using image analyzer (IMT iSolution Auto, V.9.5, IMT iSolution Inc., Canada).

Hertzian indentation tests were made on the top surfaces of YSZ coatings deposited by APS prepared from three sets of starting granules, YZ-WH, YZ-AH, and YZ-WD, using tungsten carbide (WC) sphere of radius $r=1.21 \sim$ $12.7 \mathrm{~mm}$. The indenter was driven at a constant crosshead speed $0.2 \mathrm{~mm} / \mathrm{min}$ to peak loads in universal testing machine (Instron 5567, USA). The experiments were performed to get indentation stress-strain curves for YSZ coatings at loads $P=10 \sim 500 \mathrm{~N}$. The top surfaces of the coating layer were deposited with a gold film to make the residual contact impressions visible in the Nomarski illumination of the optical microscope after polishing to $1 \mu \mathrm{m}$ diamond paste finish $[13,14]$. Then the indentation stress, $p_{0}=P / \pi a^{2}$, and indentation strain, $a / r$, were calculated from measurements of contact radius at each value of $P$ and $r$. Each indentation stress, $P / \pi a^{2}$, and indentation strain, $a / r$, was plotted after measuring the contact diameter $2 a$ for each load. In the domain of small loads where the stress-strain curves are linear proportional, Young's modulus can be calculated from [18]

$$
P_{0}=\left(\frac{3 E}{4 \pi k}\right)\left(\frac{a}{r}\right)
$$

with $k=(9 / 16)\left[\left(1-v^{2}\right)+\left(1-v^{\prime 2}\right) E / E^{\prime}\right]$ being a dimensionless coefficient, $E$ and $\nu, E^{\prime}$ and $\nu^{\prime}$ are Young's modulus
TABLE 1: The deposition condition of air plasma sprayed YSZ.

\begin{tabular}{lc}
\hline Controlled parameters & Deposition conditions \\
\hline Current $(\mathrm{A})$ & 540 \\
Primary gas, $\mathrm{Ar}(\mathrm{L} / \mathrm{min})$ & 45 \\
Secondary gas, $\mathrm{H}_{2}(\mathrm{~L} / \mathrm{min})$ & 5 \\
Deposition distance $(\mathrm{mm})$ & 150 \\
Deposition speed $(\mathrm{mm} / \mathrm{sec})$ & 500 \\
Pitch $(\mathrm{mm})$ & 4 \\
\hline
\end{tabular}

and Poisson's ratio of the material and spherical indenter, respectively.

Hertzian indentations were made at small load $(P=25 \mathrm{~N})$ intervals to determine the critical loads $P_{Y}$, the initiation load of the first surface impression, and $P_{C}$, the initiation load of the first cracking [18]. After the indentations, the surface was observed in Nomarski illumination of the optical microscope.

The coating samples were prepared for the sharp microindentation [21] and nanoindentation tests $[16,17]$. The samples were cut and ground to a $10 \mu \mathrm{m}$ finish and then polished to a $1 \mu \mathrm{m}$ finish. The surface and sections of each sample were polished with the same polishing condition. The hardness values for top coat in both planes of section and surface were determined from indentation experiments using a microindenter (HM-122, Mitutoyo Corp., Japan) for load of $10 \mathrm{~N}$, with a Vickers tip. Each value of $H$ was determined using equations reported by Lawn [22].

Nanoindentation tests were conducted on the YSZ coatings deposited from three different starting granules to determine the localized values of $H$ and $E$ using a nanoindenter (Nanoinstruments, MTS Systems Corp., Eden Prairie, USA) with a Berkovich tip (tip radius $<100 \mathrm{~nm}$ ), using the continuous stiffness measurement (CSM) option. The data were selected after indentation of up to 1,000 $\mathrm{nm}$ depth, which is corresponding to $80 \mathrm{mN}$ in the top coat. Minimum 5 indentations were conducted at the varying distance from the bond coat/topcoat interface for each sample. We calculated the hardness and elastic modulus using Oliver and Pharr $\operatorname{method}(\varepsilon=0.75)[16,17]$.

\section{Results and Discussion}

Figure 2 shows typical XRD diffractograms that were measured on the spray-dried granules prepared from different starting granules, YZ-WH, YZ-AH, and YZ-WD. The diffractograms of YSZ granules without and with heat treatment at $1250^{\circ} \mathrm{C}$ are shown in Figures 2(a) and 2(b), respectively. It is noteworthy that the monoclinic phase vanished by heat treatment. Tetragonal and cubic $\mathrm{ZrO}_{2}$ peaks were observed without any monoclinic phase after heat treatment as shown in Figure 2(b). As the monocline phase is known to transit to tetragonal phase and finally to cubic phase at high temperature, the monoclinic phase may cause cracks and defects due to volume change caused by phase transformation. The results of X-ray diffractions reveal that all spray-dried and heat-treated granules showed the same peaks.

The overall microstructure of the YSZ coating layer in cross-section direction is shown in Figure 3. The thicknesses 


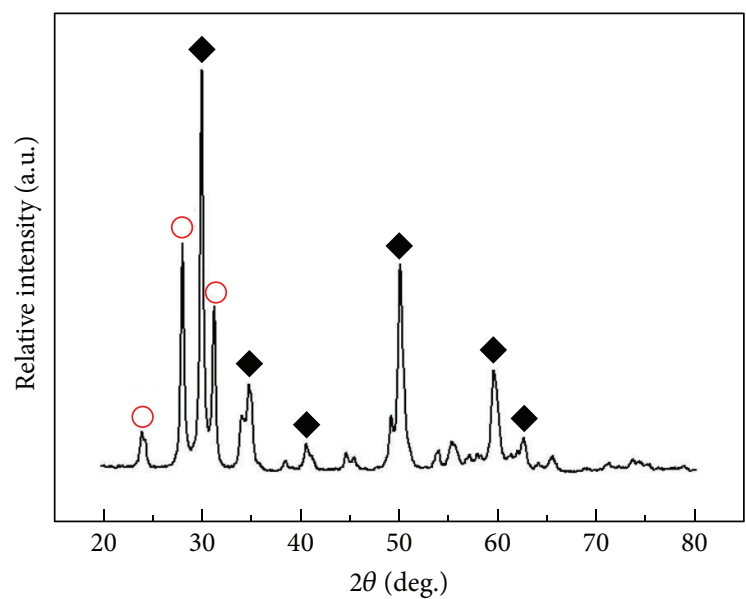

Tetra/cubic- $\mathrm{ZrO}_{2}$ - Mono- $\mathrm{ZrO}_{2}$

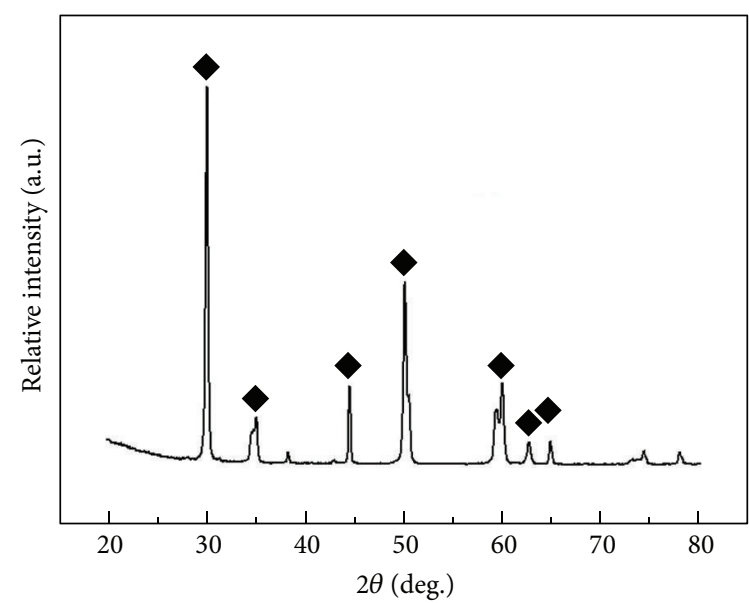

Tetra/cubic- $\mathrm{ZrO}_{2}$

Mono- $\mathrm{ZrO}_{2}$

(a)

(b)

FIGURE 2: Typical XRD diffractograms of (a) YSZ granule from spray-drying process and (b) YSZ granule after heat treatment at $1250^{\circ} \mathrm{C}$.

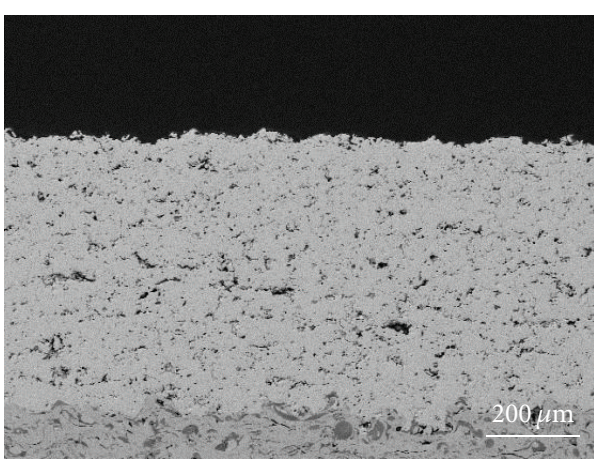

(a)

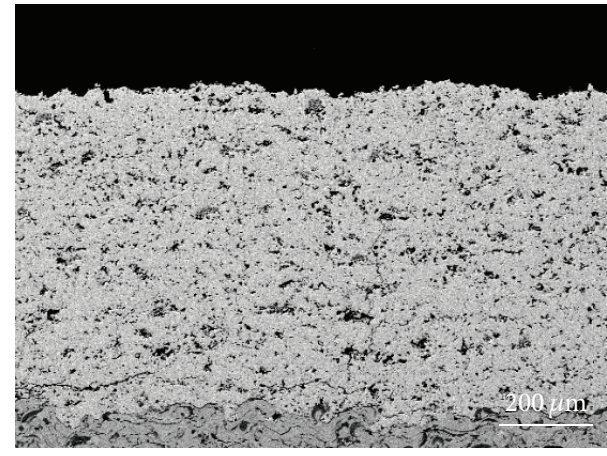

(b)

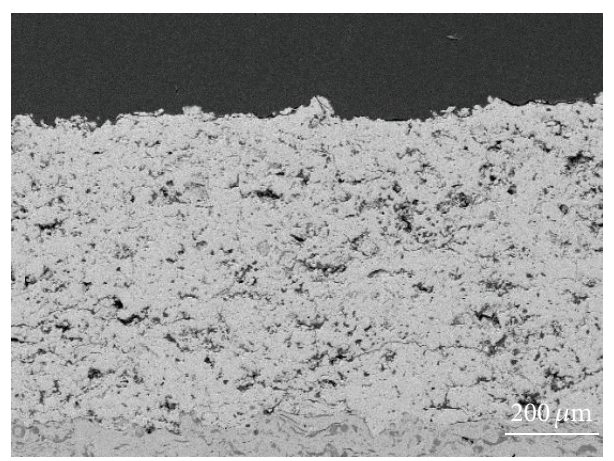

(c)

FIGURE 3: The cross-section views of SEM micrograph of 8 wt.\% YSZ APS coatings prepared from different starting granules: (a) YZ-WH, (b) YZ-AH, and (c) YZ-WD.

of the top and bond coats are $600 \sim 700 \mu \mathrm{m}$ and about $220 \sim 250 \mu \mathrm{m}$, respectively. The thicknesses of the top coat prepared from the granules of $\mathrm{YZ}-\mathrm{WH}, \mathrm{YZ}-\mathrm{AH}$, and $\mathrm{YZ}$ WD are similar to each other, indicating that the deposition conditions as shown in Table 1 are desirable to maintain the uniform coating thickness during APS. The topcoats show porosity without any detrimental cracks.
While the microstructures of the TBC observed by lowmagnified SEM pictures are similar to each other, the splat boundaries could be observed in high magnified microstructures of each top coat as shown in Figure 4 . In any case, there are lots of thick and imperfect "splat" boundaries along horizontal or vertical directions. These results indicate that the granule morphology is essential to the TBC microstructure. 


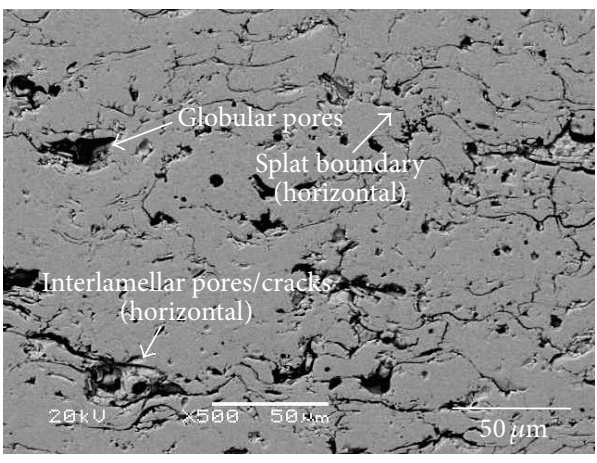

(a)

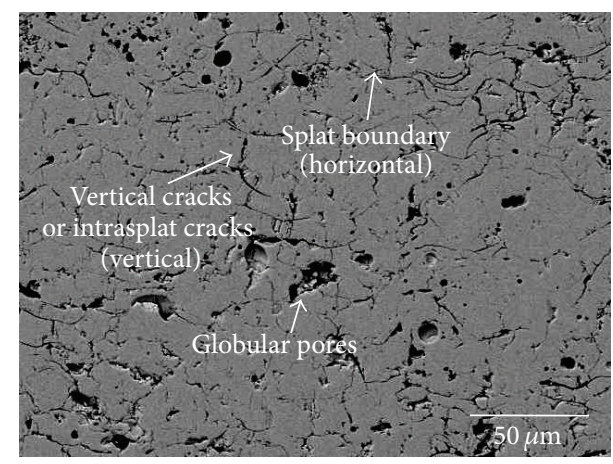

(b)

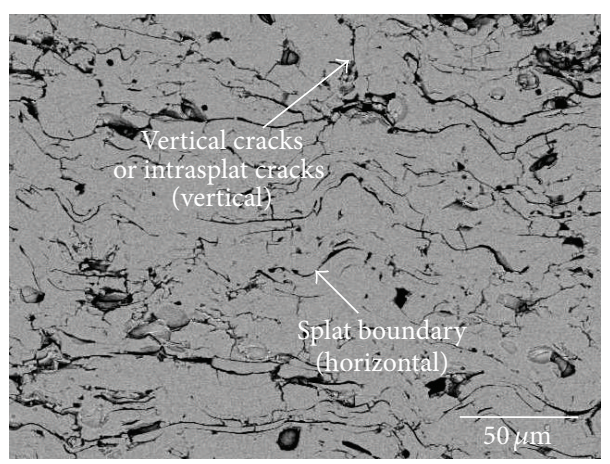

(c)

FIGURE 4: The cross-section views of SEM micrograph showing splat boundaries in $8 \mathrm{wt} . \%$ YSZ APS coatings prepared from different starting granules: (a) YZ-WH, (b) YZ-AH, and (c) YZ-WD.

Figure 5 indicates the volume percent of splat boundaries and porosities measured by image analyzer from the microstructure of the YSZ coating layer in cross-section. It is notable that the densities of splat boundaries of $\mathrm{YZ}-\mathrm{WH}$ are smaller than YZ-AH and YZ-WD. Similarly, the porosity increases through the sequence $\mathrm{YZ}-\mathrm{WH} / \mathrm{YZ}-\mathrm{AH} \cong \mathrm{YZ}-\mathrm{WD}$. The porosities of the coatings are developed from the pores in the inside of the hollowed particles and uniformity of granule size. In case of YZ-WD, higher porosity was developed during coating due to uniform size of particles even though they do not contain pores in the inside of each particle. These results indicate that the granule morphology is essential to the TBC microstructure. As it is reported that TBC with a porosity of $10 \sim 20 \%$ offers an advantage in the application of TBCs [3], the spray granules in this study are desirable for the gas turbine applications.

The indentation stress-strain curves by Hertzian indentations are shown in Figure 6. The graphs show the results for the different starting granules, YZ-WH, YZ-AH, and YZWD. The curves showed a shift away to higher stress at YZ$\mathrm{WH}$, while being strain tolerant at YZ-WD. These results indicate that the granule morphology is essential to the TBC microstructure and thus to the indentation behaviors.

The bar graph in Figure 7 indicates the measured results on the critical loads $P_{Y}$ and $P_{C}$ for YSZ coatings prepared from different starting granules, YZ-WH, YZ-AH, and YZWD. While the critical loads $P_{Y}$ depend on the hardness,

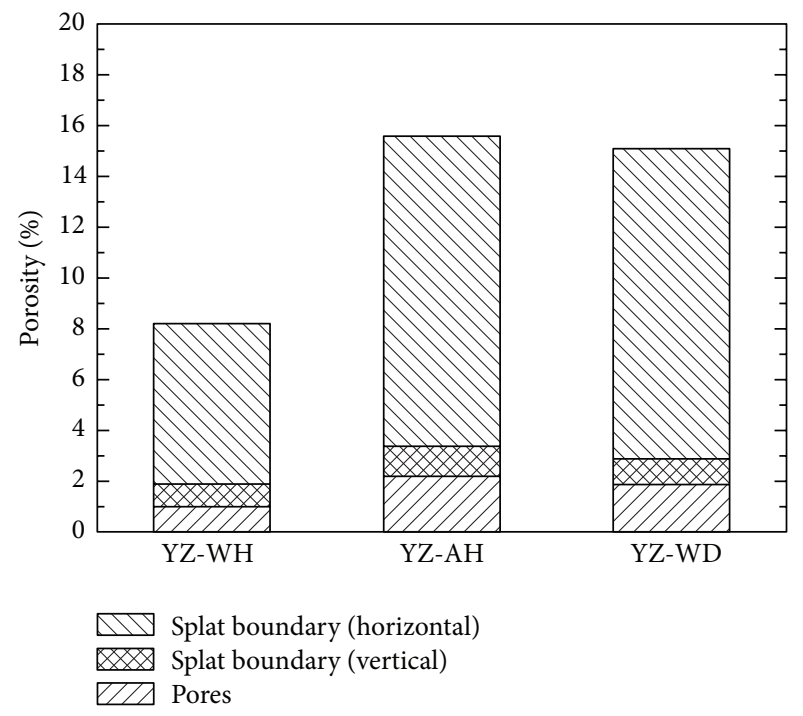

FIGURE 5: The bar graph showing porosities in $8 \mathrm{wt} . \%$ YSZ APS coatings prepared from different starting granules: $\mathrm{YZ}-\mathrm{WH}, \mathrm{YZ}-\mathrm{AH}$, and YZ-WD.

the critical loads $P_{C}$ depend on the toughness and porosity of the topcoats $[18,21]$.

The typical damage patterns found in the YSZ coatings are shown in Figure 8. Microcracks are initiated in the damage 


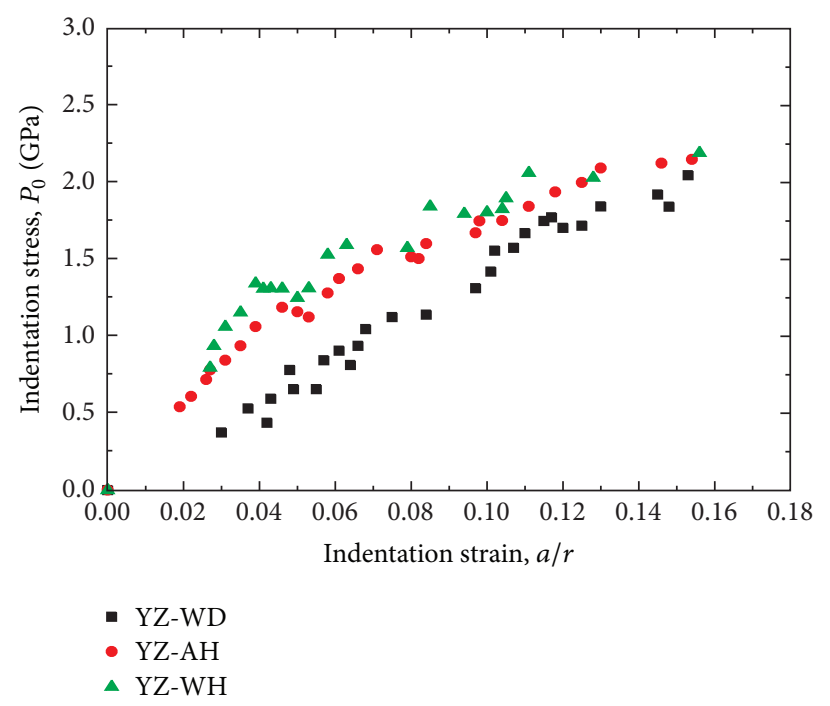

FIGURE 6: The Hertzian indentation stress-strain curves of 8 wt.\% YSZ coatings deposited from different starting granules: YZ-WH, YZ-AH, and YZ-WD.

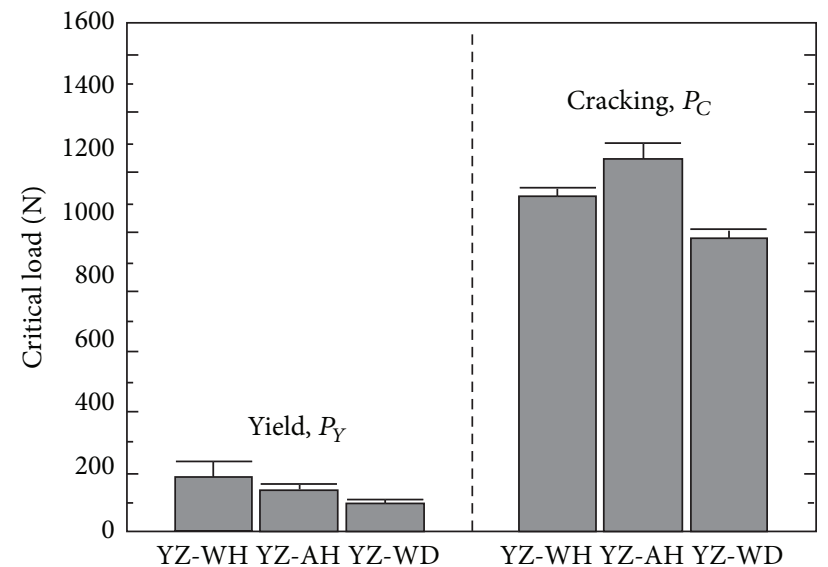

Figure 7: Bar graph showing critical loads for onset of yield, $P_{Y}$, and cracking, $P_{C}$, of YSZ coatings prepared from different starting granules: $\mathrm{YZ}-\mathrm{WH}, \mathrm{YZ}-\mathrm{AH}$, and YZ-WD, using WC sphere of radius $r=2.32 \mathrm{~mm}$.

zone, followed by ring cracks or accompanied by radial cracks according to different starting granules $[15,23]$.

Hardness measured by microindentation and developed typical damage are shown in Figure 9. The hardness data are plotted for three different starting granules. The $H$ values of the top coat prepared from YZ-WD are much lower than YZ$\mathrm{WH}$ or YZ-AH. The result that hardness decreases indicates that the measurements are influenced by microstructure such as porosities and splat boundaries within the damage regions [24].

The hardness and elastic modulus are measured by nanoindentation and then plotted as a function of the distance from the substrate to the top coating thickness, as shown in Figure 10. Note that the hardness and elastic modulus increase more at YZ-WH than YZ-WD. Plots in
Figure 10 exhibit the sensitivity of microstructure of the TBCs to hardness. The plots also show that the hardness of TBCs is sensitive to the coating thickness, indicating the decrease of mismatch at the topcoat deposited away from bond coat. Note that the hardness evaluated by nanoindentation showed higher hardness than that by microindentation, based on a comparison between Figures 9 and 10, which indicates the size effects of indentation sites as well as effect of pore volume fractions [23].

The results suggest that TBC deposited from YZ-WH may be expected to yield good hardness and mechanical properties against particle contact, foreign object damage, and wear for gas turbine applications.

\section{Conclusion}

In this study, 8 wt.\% of Yttria stabilized zirconia granules were synthesized using a coprecipitation method and transformed to soft agglomerated granules by controlling the solvent type, binder/dispersant content, and process parameters during spray-drying process. We prepared three types of granules: YZ-WH (hollow-typed granules in water based solution), YZ-AH (hollow-typed granules in alcohol based solution), and YZ-WD (dense-typed granules in water based solution). YSZ thermal barrier coatings layer had been deposited on the bond coat/Nimonic 263 substrate by APS equipment. The role of different starting granules on the coating microstructures and thus indentation properties of YSZ were investigated. The different coating microstructures were developed by varying the starting granules during the deposition. Hertzian indentation and nanoindentation are conducted on the APS YSZ coatings. All peaks are tetragonal and cubic phases without any monoclinic phase in the developed coatings. The thicknesses of the top coat prepared from three granules were similar to each other. The Hertzian indentation stressstrain curves, damage behavior by spherical indenter, and 


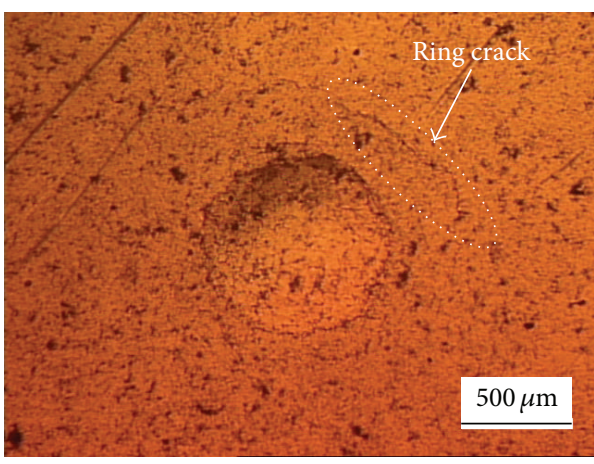

(a)

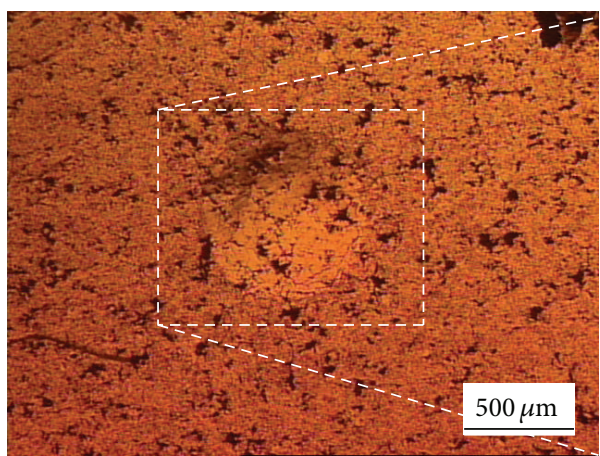

$(\mathrm{c}-1)$

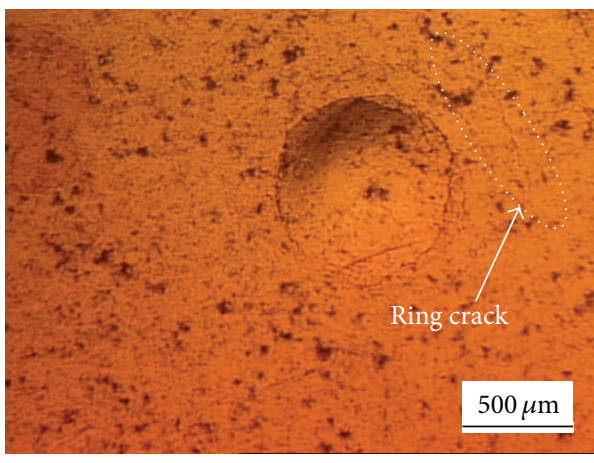

(b)

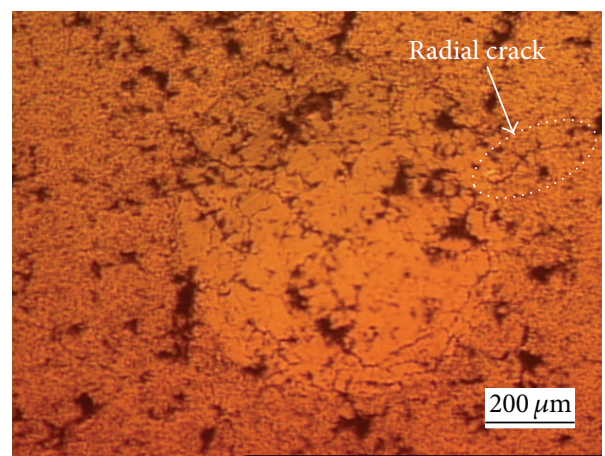

$(\mathrm{c}-2)$

(c)

FIGURE 8: Typical Hertzian indentation damage and cracks on the surface of YSZ coatings deposited by APS, using WC sphere radius $r=$ $2.32 \mathrm{~mm}$; (a), (b) ring crack damage is found in YZ-WH or YZ-AH and (c) radial crack damage is found in YZ-WD.
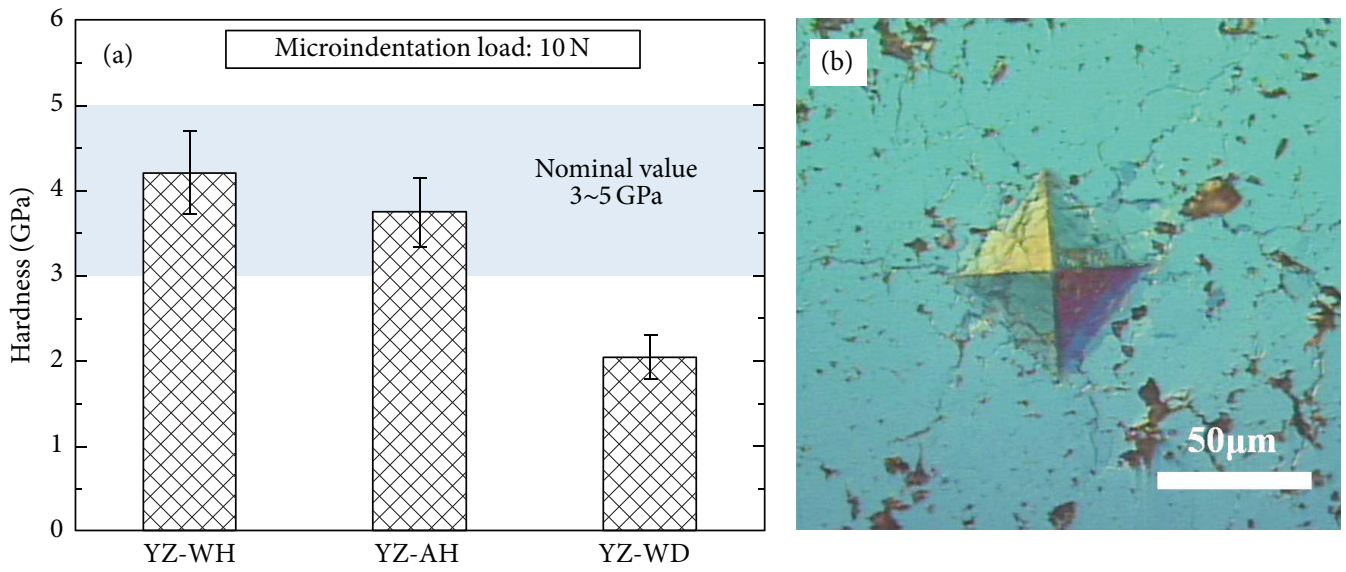

Figure 9: (a) The hardness measured by microindentation for three starting granules, YZ-WH, YZ-AH, and YZ-WD, and (b) typical indentation damage developed in YZ-WH samples at load $P=10 \mathrm{~N}$.

hardness by microindentation and nanoindentation were investigated according to the different microstructures. As a result, the relatively porous microstructure could be obtained from the monodisperse granules synthesized in water based solution, YZ-WD, while the coating layer from hollow-typed granules, YZ-WH, shows relatively dense microstructure. The hardness values measured by microindentations or hardness and elastic modulus by nanoindentations are governed by microstructure of the TBC coatings. The results indicate that the TBC deposited from YZ-WH granules may be expected to yield good wear properties for gas turbine applications.

\section{Conflict of Interests}

The authors declare that there is no conflict of interests regarding the publication of this paper. 

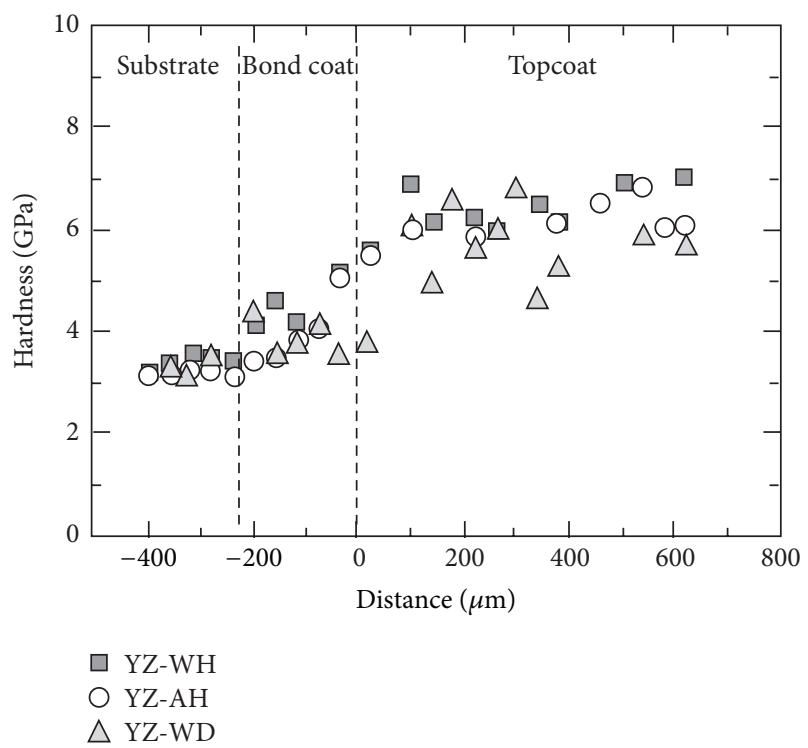

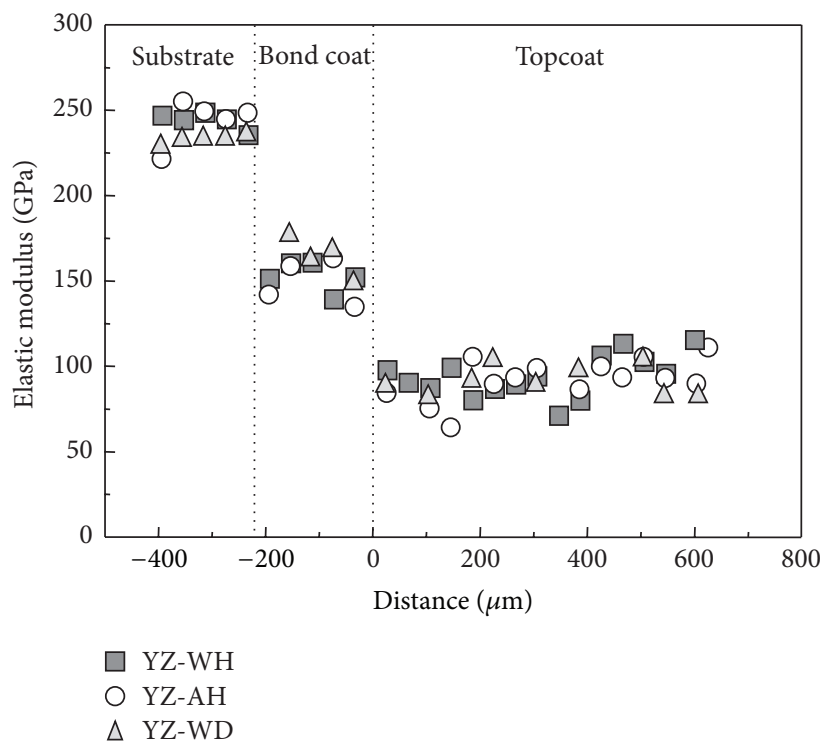

(b)

(a)

FIGURE 10: (a) Hardness and (b) elastic modulus of YSZ coatings prepared from different starting granules: YZ-WH, YZ-AH, and YZ-WD. The hardness and elastic modulus measurements are from nanoindentations.

\section{Acknowledgments}

This work was partly supported by the IT R\&D program of MOTIE/KEIT (no. 10043795, Development of Materials for Gas Turbine Operated at $1600^{\circ} \mathrm{C}$ for High-Efficiency Power Generation) and conducted by research program 2014 of Kookmin University.

\section{References}

[1] S. Bose and D. Marcin, "Thermal barrier coating experience in gas turbine engines at Pratt \& Whitney," Journal of the Thermal Spray Technology, vol. 6, no. 1, pp. 99-104, 1997.

[2] X. Q. Cao, R. Vassen, and D. Stoever, "Ceramic materials for thermal barrier coatings," Journal of the European Ceramic Society, vol. 24, no. 1, pp. 1-10, 2004.

[3] E. P. Busso, Z. Q. Qian, M. P. Taylor, and H. E. Evans, “The influence of bondcoat and topcoat mechanical properties on stress development in thermal barrier coating systems," Acta Materialia, vol. 57, no. 8, pp. 2349-2361, 2009.

[4] S.-W. Myoung, J.-H. Kim, W.-R. Lee, Y.-G. Jung, K.-S. Lee, and U. Paik, "Microstructure design and mechanical properties of thermal barrier coatings with layered top and bond coats," Surface and Coatings Technology, vol. 205, no. 5, pp. 1229-1235, 2010.

[5] K. M. Grant, S. Krämer, J. P. A. Löfvander, and C. G. Levi, "CMAS degradation of environmental barrier coatings," Surface and Coatings Technology, vol. 202, no. 4-7, pp. 653-657, 2007.

[6] S. T. Aruna, B. A. Paligan, N. Balaji, and V. P. Kumar, "Properties of plasma sprayed yttria stabilized zirconia thermal barrier coating prepared from co-precipitation synthesized powder," Ceramics International, vol. 40, no. 7, pp. 11157-11162, 2014.

[7] R. Xu and O. A. Di Guida, "Comparison of sizing small particles using different technologies," Powder Technology, vol. 132, no. 23, pp. 145-153, 2003.
[8] S. J. Lukasiewicz, "Spray-drying ceramic powders," Journal of the American Ceramic Society, vol. 72, no. 4, pp. 617-624, 1989.

[9] B. Ercan, K. J. Bowman, R. W. Trice, H. Wang, and W. Porter, "Effect of initial powder morphology on thermal and mechanical properties of stand-alone plasma -sprayed $7 \mathrm{wt} . \%$ $\mathrm{Y}_{2} \mathrm{O}_{3}-\mathrm{ZrO}_{2}$ coatings," Materials Science and Engineering A, vol. 435-436, pp. 212-220, 2006.

[10] A. D. Jadhav and N. P. Padture, "Mechanical properties of solution-precursor plasma-sprayed thermal barrier coatings," Surface and Coatings Technology, vol. 202, no. 20, pp. 49764979, 2008.

[11] R. G. Wellman and J. R. Nicholls, "Erosion, corrosion and erosion-corrosion of EB PVD thermal barrier coatings," Tribology International, vol. 41, no. 7, pp. 657-662, 2008.

[12] S. Guo and Y. Kagawa, "Effect of loading rate and holding time on hardness and Young's modulus of EB-PVD thermal barrier coating," Surface and Coatings Technology, vol. 182, no. 1, pp. 92100, 2004.

[13] A. Pajares, L. Wei, B. R. Lawn, N. P. Padture, and C. C. Berndt, "Mechanical characterization of plasma sprayed ceramic coatings on metal substrates by contact testing," Materials Science and Engineering: A, vol. 208, no. 2, pp. 158-165, 1996.

[14] A. Pajares, L. Wei, B. R. Lawn, and C. C. Berndt, "Contact damage in plasma-sprayed alumina-based coatings," Journal of the American Ceramic Society, vol. 79, no. 7, pp. 1907-1914, 1996.

[15] K. S. Lee, S. K. Lee, B. R. Lawn, and D. K. Kim, “Contact damage and strength degradation in brittle/quasi-plastic silicon nitride bilayers," Journal of the American Ceramic Society, vol. 81, no. 9, pp. 2394-2404, 1998.

[16] G. M. Pharr, W. C. Oliver, and F. R. Brotzen, "On the generality of the relationship among contact stiffness, contact area, and elastic modulus during indentation," Journal of Materials Research, vol. 7, no. 3, pp. 613-617, 1992.

[17] W. C. Oliver and G. M. Pharr, "Improved technique for determining hardness and elastic modulus using load and 
displacement sensing indentation experiments," Journal of Materials Research, vol. 7, no. 6, pp. 1564-1580, 1992.

[18] B. R. Lawn, "Indentation of ceramics with spheres: a century after Hertz," Journal of the American Ceramic Society, vol. 81, no. 8, pp. 1977-1994, 1998.

[19] R. B. King, "Elastic analysis of some punch problems for a layered medium," International Journal of Solids and Structures, vol. 23, no. 12, pp. 1657-1664, 1987.

[20] C. Kim, Y. S. Heo, T. W. Kim, and K. S. Lee, "Fabrication and characterization of zirconia thermal barrier coatings by spray drying and atmospheric plasma spraying," Journal of the Korean Ceramic Society, vol. 50, no. 5, pp. 326-332, 2013.

[21] K. Duan and R. W. Steinbrech, "Influence of sample deformation and porosity on mechanical properties by instrumented microindentation technique," Journal of the European Ceramic Society, vol. 18, no. 2, pp. 87-93, 1998.

[22] B. R. Lawn, "Special applications of the indentation method," in Cambridge Solid State Science Series: Fracture of Brittle Solids, vol. 2, pp. 296-299, Cambridge University Press, New York, NY, USA, 2nd edition, 1993.

[23] S. H. Park, S. K. Kim, T. W. Kim, U. Paik, and K. S. Lee, "Indentation on YSZ thermal barrier coating layers deposited by electron beam PVD," Philosophical Magazine, vol. 86, no. 3335, pp. 5453-5463, 2006.

[24] J.-Y. Kwon, J.-H. Lee, H.-C. Kim, Y.-G. Jung, U. Paik, and K.-S. Lee, "Effect of thermal fatigue on mechanical characteristics and contact damage of zirconia-based thermal barrier coatings with HVOF-sprayed bond coat," Materials Science and Engineering A, vol. 429, no. 1-2, pp. 173-180, 2006. 

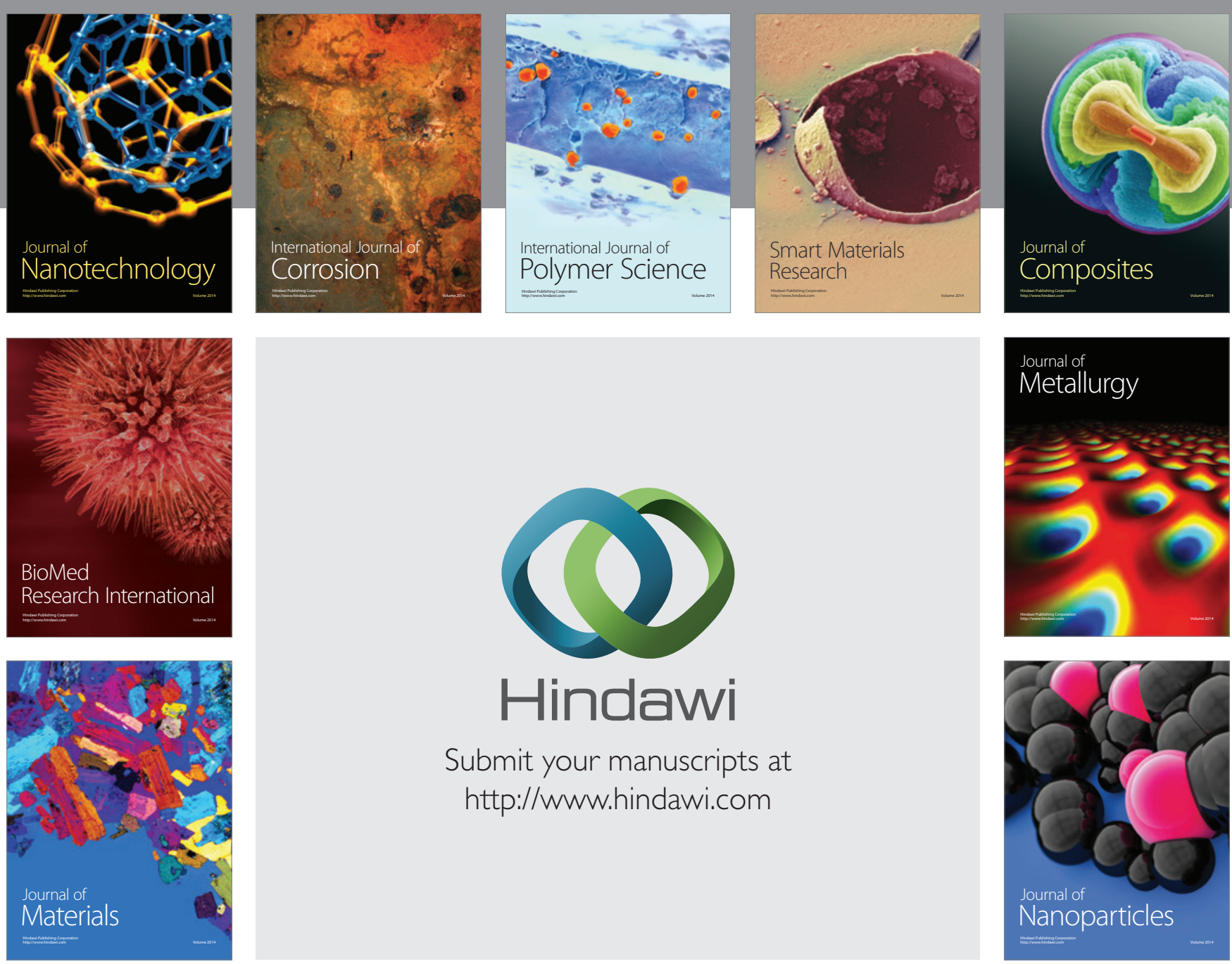

Submit your manuscripts at http://www.hindawi.com
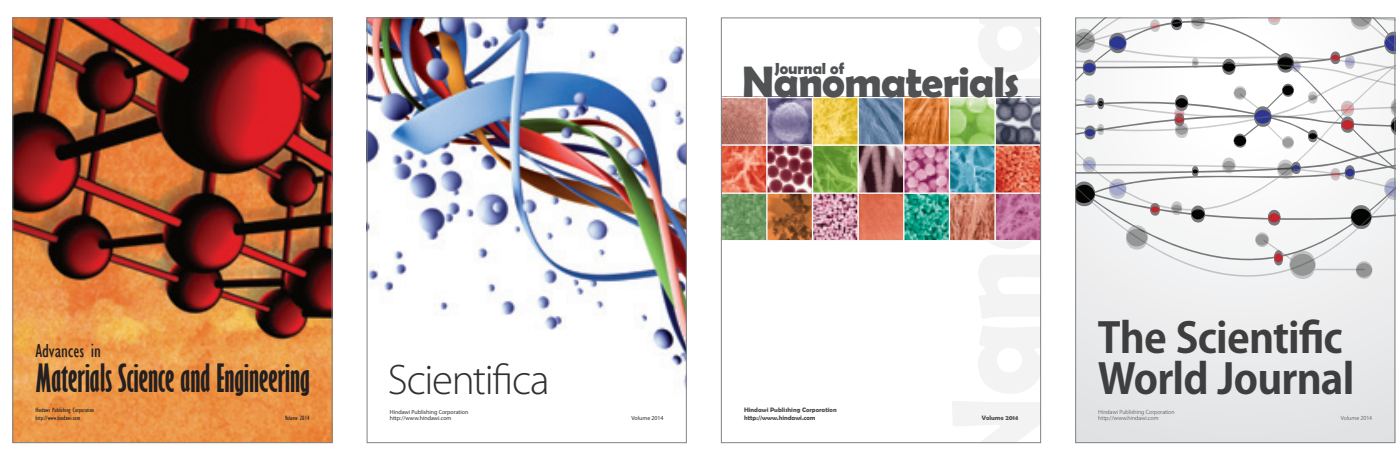

\section{The Scientific World Journal}
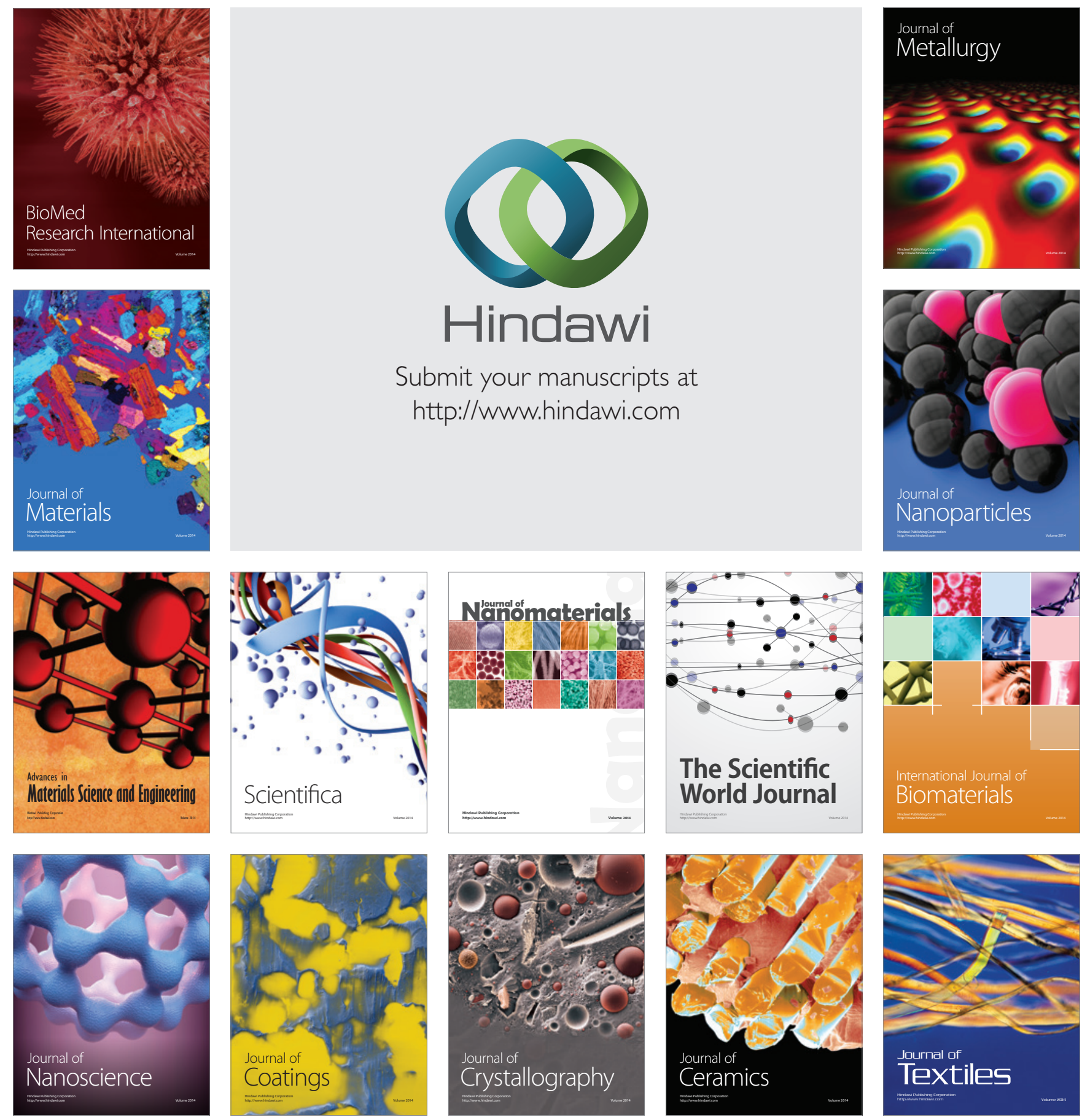